\title{
Urban design, safety, livability, \& accessibility
}

\author{
Mahyar Arefi ${ }^{1} \cdot$ Noha Nasser ${ }^{1}$
}

Accepted: 2 February 2021 / Published online: 26 February 2021

(c) The Author(s), under exclusive licence to Springer Nature Limited part of Springer Nature 2021

While urban designers do acknowledge the significance of the transportation infrastructure in the city, they do not frequently pay attention to some of their particular ramifications or implications-especially, in microscales, including the impacts of bus stops and sidewalk design on placemaking, the pedestrians' perception of local safety, or the width and spacing of parking isles and traffic calming devices as potential design solutions. More often than not, some of these aspects get sidetracked in the bigger scheme of things, or at the expense of other priorities. This issue of Urban Design International focuses on some of these seemingly mundane, but nevertheless important aspects of the transportation infrastructure and street network often overlooked in urban design praxis. More specifically, it explores the nexus between urban design, perceived safety, street livability, and accessibility.

In the first article, Aura-Luciana Istrate et al., revisited the notion of street livability in Shanghai, China. Stemmed from a belated concern that factors in the cultural differences between the Western and non-Western contexts, the authors conceptualized a new framework that includes the humanized environment, physical facilities, economic activities, safety, social interaction, and sense of place as its constituent components, some of which are quantifiable and some remain subjective. Street safety, as expected, plays a key role in this framework. Urban designers can also integrate micro-scale design considerations to improve street safety. Lesan and Gjerde, for example, have explored these options in a multi-cultural context. People do not have to jeopardize their lives trying to negotiate tight traffic jams while walking or observing. Landscaping and "sociopetal seating" options can help protect the carefully located and designed street furniture to boost social interaction and place attachment.

While safety plays instrumental roles in street livability, the other articles in this issue delve deeper into

Mahyar Arefi

mahyararefi@gmail.com

1 Arlington, USA its multifarious aspects. For example, Johan Rahm et al., explore four related themes associated with perceived safety-especially, after dark. Avoidance, entrapment, pressure of others, and prospect (i.e., the "visual overview of the nearby surroundings") constitute the four themes associated with the perceived public safety in using the local parks after dark notwithstanding the availability of street lighting and lush greenery. The findings of this research confirm public perception is a highly complex phenomenon, be it relative to the built environment, urban green/open space, or social behavior.

Nawaf Alhajaj and Daghistani conducted a somewhat different study on safety and accessibility in a car-dominant university campus in Saudi Arabia. The authors used a survey questionnaire and a walking route checklist, and aimed to validate their findings by triangulation. Their findings, among other things, include reducing traffic speed inside offstreet and parking and traffic calming strategies. They also approved the role of design (i.e., off-street parking design or designing narrow rather than wide double-loaded parking isles) in increasing the population of safety among students.

The other authors in this issue focused on additional aspects of walkability in the urban settings. Yang et al., for example, focused on the "detrimental impacts" of "car-oriented transport infrastructure" in the public realm. Using a qualitative research method, the authors highlighted the role of a holistic design strategy for creating "pedestrian-friendly transport, public space systems." Using an "agent-based modeling and serious gaming with a co-design approach," they increased the citizens' involvement in designing an integrated TIPS (Transport Infrastructure, and Public Space) system. In a way, the authors attempted to combine both qualitative as well as quantitative visualization techniques in what they consider a co-design method that would help urban designers to expand the Lynchian approach toward cognitive mapping, thereby, examining environmental performance and inclusive design.

In "Design as if bus stops mattered: exploring the potential role of public transport stops in the urban environment," Elisabette Vitale Brovarone casts another angle on the role 
of the public transportation system, particularly, bus stops, and its nexus to urban design. Underlining urban designers' neglect of bus stops in their design strategies, she proposes imageability (designs that evoke place meaning), belonging (a visual identifier that helps to better remember a bus stop as a result of how it looks even though it might be just positioned in a context as an extraneous and not a local object), transparency ("combining transparency and visibility to and from the surroundings"), usability (features that make "waiting a pleasant experience rather than a waste of time"), and accessibility (both physical as well as virtual) as five design principles that can help bolster and shape vivid public spaces.

Finally, in "Rail Villages" in Hong Kong: development ratio and design factors," Xue and Sun look at the flipside of public space, transportation infrastructure and walkability relationships. That is, they essentially delve deeper into the notion of development density both subjectively (i.e., perceived by the public) and objectively (in a fairly dense city like Hong Kong). The density problem, among other things, can impose additional design problems for people as well as policymakers.

The papers in this issue address important design-related issues for policymakers, practitioners, and academics alike. We believe that the compilation of these ideas and their connection to urban design praxis stimulates further potential discussion among scholars and practitioners for more robust solutions for the future contemporary challenges facing our cities.

Publisher's Note Springer Nature remains neutral with regard to jurisdictional claims in published maps and institutional affiliations. 